\title{
Preparation And Characterization of g- $\mathrm{C}_{3} \mathrm{~N}_{4}$ @ L- Arginine As A Highly - Efficient And Recyclable Catalyst For The Synthesis of 1, 4-Dihydropyridine, 4H- Chromene, And 2, 3-Dihydro Quinazoline Derivatives
}

\author{
Zeinab Tajik \\ Iran University of Science and Technology \\ Hossein Ghafuri ( $\square$ ghafuri@iust.ac.ir) \\ Iran University of Science and Technology \\ Nastaran Ghanbari \\ Iran University of Science and Technology \\ Payman Hanifehnejad \\ Iran University of Science and Technology
}

\section{Research Article}

Keywords: g-C3N4@L-arginine,4H-chromene, 2, 3-dihydro quinazoline, 1, 4-dihydropyridine, reusability of nanocatalyst

Posted Date: April 30th, 2021

DOI: https://doi.org/10.21203/rs.3.rs-462994/v1

License: @ (i) This work is licensed under a Creative Commons Attribution 4.0 International License. Read Full License 


\section{Abstract}

In this work, the nanocatalyst of g- $\mathrm{C}_{3} \mathrm{~N}_{4} @ \mathrm{~L}$-arginine was prepared that synthesis of it in comparison with the synthesis of other catalysts was convenient; initially, this prepared nanocatalyst was evaluated and verified by FT-IR, EDX, XRD, TGA, and FESEM analysis, and in the next step, the performance of nanocatalyst in the synthesis of 1, 4-dihydropyridine, 4H-chromene, and 2, 3-dihydro quinazoline derivatives were examined with high yield. Properties such as high thermal stability, easy separation of reaction media, use in various multicomponent reactions, and reusability have caused that this novel nanocatalyst was changed into a unique catalyst in its own age.

\section{Introduction}

In recent decades, the use of a suitable catalytic substrate has become more demanding and interesting for chemistry researchers ${ }^{1-4}$. Therefore, the preparation and use of catalysts with suitable substrates have been considered. $\mathrm{g}-\mathrm{C}_{3} \mathrm{~N}_{4}$ is widely used as a heterogeneous catalytic substrate due to its advantages such as excellent physical, chemical, and thermal stability, abrasion resistance, high hardness and low density, versatile performance, low cost for synthesis, and recyclability ${ }^{5,6}$.

Modification of catalysts by different groups is an important and fundamental task to improve the performance of the catalyst. For a variety of reasons, such as toxicity, high cost, etc., in organic synthesis, the use of metal-free catalysts is cost-effective, so metal-free approaches have become more preferred in recent decades ${ }^{7}$.

Recently, amino acids with advantages such as high acidity, ability to bind to catalytic substrates and low preparation cost are good catalytic agents for improving the performance of catalysts.

Arginine is one of the main and semi-essential amino acids in the body of living organisms that with $\mathrm{PKa}=$ 2.48 can be used as an acidic catalytic agent on the surface of $\mathrm{g}-\mathrm{C}_{3} \mathrm{~N}_{4}$ nanosheets and also be used as an effective catalyst in organic reactions.compounds.

Heterocyclic compounds have been one of the best compounds in organic synthesis and pharmaceutical chemistry. Heterocyclic compounds are mainly used as medicines, chemicals, veterinary products, disinfectants, expanders, and antioxidants ${ }^{8}$.

The conditions of green chemistry, the use of inexpensive, non-toxic reagents, and produce low waste in organic reactions are of great importance for the synthesis of compounds. Hence, multicomponent reactions (MCRs) are considered a useful method for the synthesis of heterocyclic organic molecules. A significant advantage of multicomponent reactions is the elimination of intermediates. Also, short reaction times, high yield, and easy separation of products make such reactions more crucial ${ }^{9-12}$.

Compounds such as 1, 4-dihydropyridine, tetrahydro-4H-chromenes, and dihydro quinazolines have a high medicinal activity that synthesizes by multicomponent reactions. 
Dihydropyridines are classified into two classes: symmetrical and asymmetrical dihydropyridines. Asymmetrical dihydropyridines are synthesized by the reaction between an aldehyde, $2 \mathrm{mmol}$ of two different $\beta$-keto esters, and a nitrogen donor such as ammonium acetate or ammonia. The product of the initial reaction is dihydropyridine that can later be converted to pyridine. These compounds are an important class of antihypertensive drugs, vasodilators, Hypnotic, anti-tumor ${ }^{13,14}$, anti-inflammatory ${ }^{15,16}$, anti-diabetic, antianxiety, anti-mutation, and they are known as calcium channel blockers ${ }^{17}$.

Tetrahydro-4H-chromenes are an important class of heterocyclic compounds with simple structure and low side effects; that they are synthesized by the single-step condensation of aldehydes with malononitrile and dimedone ${ }^{18}$. Beside their various derivatives have important activities such as anticancer, antiviral, antiinflammatory, antibacterial, antifungal, antioxidant, anticoagulant; they are also used as cognitive enhancers to treat Alzheimer's disease ${ }^{19,20}$.

Dihydroquinazolines are the building blocks of about 150 natural alkaloids, and these compounds are prepared by the reaction between aldehydes, isotonic anhydride, and ammonium acetate. Moreover, they have a range of pharmaceutical and biological activities like anti-inflammatory, antimalarial, antibacterial, anticancer, antiviral activities ${ }^{21,22}$.

Hence, many efforts have been made to synthesize such high-yield compounds. There are many methods for the synthesis of these compounds that have been prepared by using various catalysts such as MCM$41 @ S c h i f f$ base-Co $(\mathrm{OAC})_{2}{ }^{23}, \mathrm{Yb}\left(\mathrm{NPf}_{2}\right)_{3}{ }^{24}, \mathrm{MCM}-41 @$ @serine@Cu(II) ${ }^{25}$, Titanium silicon oxide nanopowder ${ }^{26}$, $\mathrm{Y}\left(\mathrm{NO}_{3}\right)_{3} \cdot 6 \mathrm{H}_{2} \mathrm{O}^{27}$, and etc. Although these catalysts are effective some of them have limitations such as long reaction time, expensive reagent, and the possibility of their contamination in final products.

Here, a new catalyst ( $\mathrm{g}-\mathrm{C}_{3} \mathrm{~N}_{4}$ @ L-arginine) with the ability to perform various multi-combination reactions with a high yield, short reaction time, recyclability, and easy separation conditions from the reaction mixture is reported

\section{Results And Discussion}

The g- $\mathrm{C}_{3} \mathrm{~N}_{4} @ \mathrm{~L}$-arginine synthesis process consists of three main steps that were shown in scheme 1. The first step is the synthesis of nanosheet $\mathrm{g}-\mathrm{C}_{3} \mathrm{~N}_{4}$ from melamine, which melamine was polymerized to bulk $\mathrm{g}-\mathrm{C}_{3} \mathrm{~N}_{4}$, then nanosheet $\mathrm{g}-\mathrm{C}_{3} \mathrm{~N}_{4}$ is synthesized by liquid exfoliation and sonication. In the second step, the nanosheets $\mathrm{g}-\mathrm{C}_{3} \mathrm{~N}_{4}$ was modified by 1,3 -dibromooropane at $100{ }^{\circ} \mathrm{C}$ for $24 \mathrm{~h}$ under a nitrogen atmosphere, and in the last stage, the $\mathrm{g}-\mathrm{C}_{3} \mathrm{~N}_{4} @ \mathrm{~L}$-arginine was prepared from the reaction between L-arginine and modified nanosheets $\mathrm{g}$ $\mathrm{C}_{3} \mathrm{~N}_{4}$. In this work, various techniques such as FT-IR, EDX, XRD, FESEM, and TGA have been used to identify and characterize the properties of this novel nanocatalyst, which have been examined in the following.

In Fig. 1, the FT-IR spectra of nanosheets g- $\mathrm{C}_{3} \mathrm{~N}_{4}$ and g- $\mathrm{C}_{3} \mathrm{~N}_{4} @ \mathrm{~L}$-arginine is shown. Figure 1(a) a strong and broad peak appeared in the range $3300-3000 \mathrm{~cm}^{-1}$, which is related to stretching vibration of $\mathrm{N}-\mathrm{H}$ bonds, breadth peak can be assigned to $\mathrm{N}-\mathrm{H}$ groups involved in $\mathrm{H}$-bonding or the presence of $\mathrm{O}-\mathrm{H}$ groups due to water adsorption by nanosheets $\mathrm{g}-\mathrm{C}_{3} \mathrm{~N}_{4}{ }^{28,29}$. The stretching vibration peak of $\mathrm{C}=\mathrm{N}$ was observed at $1602 \mathrm{~cm}^{-1}$. The 
peaks at 1303 and $1082 \mathrm{~cm}^{-1}$ are attributed to the stretching vibration of C-N bonds formed between triazine and $\mathrm{N}-\mathrm{H}$ groups, and the stretching vibration of $\mathrm{C}-\mathrm{N}$ bonds in the ring was easily visible at 1448 and $1379 \mathrm{~cm}^{-}$ 129,30 . In addition to the peak of $786 \mathrm{~cm}^{-1}$ is due to the vibration of tri-s-triazine units ${ }^{1}$.

Figure 1(b) shows that the nanosheets $\mathrm{g}-\mathrm{C}_{3} \mathrm{~N}_{4}$ was modified with 1,3- dibromopropane; the peak of 3000 $2800 \mathrm{~cm}^{-1}$ is related to $\mathrm{C}-\mathrm{H}$ stretching vibration.

In Fig. 1(c), the g- $\mathrm{C}_{3} \mathrm{~N}_{4} @ \mathrm{~L}$-arginine spectrum is presented that the existence of L-arginine on the surface of nanosheets $\mathrm{g}-\mathrm{C}_{3} \mathrm{~N}_{4}$ is authenticated by stretching vibration of $\mathrm{C}=\mathrm{O}\left(1705 \mathrm{~cm}^{-1}\right)$ and $\mathrm{C}-\mathrm{O}\left(1320-1210 \mathrm{~cm}^{-1}\right)$ because $\mathrm{O}-\mathrm{H}$ and $\mathrm{C}-\mathrm{H}$ bonds already existed in the structure of modified nanosheets $\mathrm{g}-\mathrm{C}_{3} \mathrm{~N}_{4}$.

The presence of essential elements at each step of catalyst synthesis was determined by EDX analysis.

In Fig. 2(a), the presence of carbon and nitrogen elements in the structure of nanosheets $\mathrm{g}-\mathrm{C}_{3} \mathrm{~N}_{4}$ is visible. In the next step, the presence of Br element in structure proves that nanosheets $\mathrm{g}-\mathrm{C}_{3} \mathrm{~N}_{4}$ was modified by $1,3-$ dibromopropane (Fig. 2(b)). Moreover, in the final structure ( $\mathrm{g}-\mathrm{C}_{3} \mathrm{~N}_{4} @ \mathrm{~L}$-arginine), the presence of elements such as carbon, nitrogen, and oxygen confirmed the synthesis of g- $\mathrm{C}_{3} \mathrm{~N}_{4} @ \mathrm{~L}$-arginine (Fig. 2(c)).

The morphology of nanosheets g- $\mathrm{C}_{3} \mathrm{~N}_{4}$ and g- $\mathrm{C}_{3} \mathrm{~N}_{4} @ \mathrm{~L}$-arginine was investigated by FE-SEM.

In Fig. 3(a, b, c, d), the FESEM images of nanosheets g-C3N4 are shown. In Figures (a), (b) and (c) as expected, the nanosheets $\mathrm{g}-\mathrm{C}_{3} \mathrm{~N}_{4}$ have a smooth and flat surface. In Figure (d), nanosheets $\mathrm{g}-\mathrm{C}_{3} \mathrm{~N}_{4}$ plates are clearly seen that are irregular and connected together. In figure (e-i), FESEM images of g- $\mathrm{C}_{3} \mathrm{~N}_{4} @ \mathrm{~L}$-arginine are shown; Figures ( $e$ and $g$ ) show that the nanosheets $\mathrm{g}-\mathrm{C}_{3} \mathrm{~N}_{4}$ have a flake structure and is not entirely smooth, which is the reason for the presence of L-arginine on it. In Figure (i), the nanosheets $\mathrm{g}-\mathrm{C}_{3} \mathrm{~N}_{4}$ plates are still visible, but they have become a little more irregular. The surface of nanosheets $\mathrm{g}-\mathrm{C}_{3} \mathrm{~N}_{4}$ is covered with tiny particles that substantiate the presence of L-arginine on the surface of nanosheets $\mathrm{g}-\mathrm{C}_{3} \mathrm{~N}_{4}$.

XRD patterns of nanosheets g- $\mathrm{C}_{3} \mathrm{~N}_{4}$ and g- $\mathrm{C}_{3} \mathrm{~N}_{4} @ \mathrm{~L}$-arginine were provided in Fig. 4a-b. Part (a) is related to the XRD pattern of nanosheets $\mathrm{g}-\mathrm{C}_{3} \mathrm{~N}_{4}$ with diffraction angles of $2 \theta=27.69$ and $2 \theta=15.96$ that proves nanosheets $\mathrm{g}-\mathrm{C}_{3} \mathrm{~N}_{4}$ synthesis ${ }^{1,7,28}$. In part (b) is shown XRD pattern of g- $\mathrm{C}_{3} \mathrm{~N}_{4} @ \mathrm{~L}$-arginine, diffraction angles of $2 \theta=6.07,10.85,12.21,23.60,30.97$ corresponded to the standard XRD pattern of L-arginine (Ref.code NO. 00-004-0180). According to obtained results from the observed diffraction angles, the presence of L-arginine in the catalyst structure was confirmed.

Figure 5 shows the thermal stability of the synthesized g- $\mathrm{C}_{3} \mathrm{~N}_{4} @ \mathrm{~L}$-arginine in the thermal range of $50-800^{\circ} \mathrm{C}$. As could be seen, at the temperature of 100 to $200^{\circ} \mathrm{C}$, bit by bit, the weight ratio has decreased, which is most likely related to the removal of water absorbed by the g- $\mathrm{C}_{3} \mathrm{~N}_{4} @ \mathrm{~L}$-arginine surface. Then, another weight loss is observed at a range of 200 to $400^{\circ} \mathrm{C}$, which is due to L-arginine's separation from the desired structure. Finally, at the temperature of 400 to $700^{\circ} \mathrm{C}$, we saw a downward trend in the curve, that related to decompose of nanosheets $\mathrm{g}-\mathrm{C}_{3} \mathrm{~N}_{4}{ }^{31}$. 


\section{General procedure for the synthesis of 1, 4-dihydropyridine, 4H-chromene, and 2,3-dihydro quinazoline derivatives}

In this section, we evaluated the performance of the $\mathrm{g}-\mathrm{C}_{3} \mathrm{~N}_{4} @ \mathrm{~L}$-arginine in the synthesis of 1, 4-dihydropyridine, $4 \mathrm{H}$-chromene, and 2, 3-dihydro quinazoline derivatives. For this purpose, various parameters such as reaction time, amount of catalyst, and the solvent were examined (Table 1). The reaction of 4-chlorobenzaldehyde $(1 \mathrm{mmol})$,ethyl acetoacetate $(1 \mathrm{mmol})$, dimedone $(1 \mathrm{mmol})$, and ammonium acetate $(1 \mathrm{mmol})$ for synthesis of $1,4-$ dihydropyridine derivatives, reaction of 4-chlorobenzaldehyde $(1 \mathrm{mmol})$,

dimedone $(1 \mathrm{mmol})$, and malononitrile $(1 \mathrm{mmol})$ for synthesis of $4 H$ chromene derivatives, and reaction of 4 chlorobenzaldehyde $(1 \mathrm{mmol})$, isotonic anhydride $(1 \mathrm{mmol})$, and ammonium acetate $(1 \mathrm{mmol})$ for synthesis of 2,3-dihydro quinazoline derivatives were used as model reactions in aid of optimize the reaction condition. Initially, reactions in the absence of g- $\mathrm{C}_{3} \mathrm{~N}_{4} @ \mathrm{~L}$-arginine were investigated under different conditions, and TLC monitored the reaction process. However, as can see in Table 1, no progress was observed in the process of model reactions (Table 1,entries 1, 2). In the next step, in the presence of 1.00mg of g- $\mathrm{C}_{3} \mathrm{~N}_{4} @ \mathrm{~L}$-arginine, reaction progress was easily visible compared to its absence (Table 1,entry3), which indicates that the g$\mathrm{C}_{3} \mathrm{~N}_{4} @ \mathrm{~L}$-arginine is a leading factor in the progress of the reaction. Then, by changing the amount of catalyst, reaction time, and solvent, the best conditions for model reactions were examined. As was seen, the time increment did not have a specific effect in reaction progression and the optimum reaction time was 15 min for all three model reactions (Table 1,entries7,8, and 9). Furthermore, the highest yield of products was obtained in the presence of $20.00 \mathrm{mg}$ of $\mathrm{g}-\mathrm{C}_{3} \mathrm{~N}_{4} @ \mathrm{~L}$-arginine and using ethanol at $80^{\circ} \mathrm{C}$ (Table 1,entry 5).

In the following, various aldehydes were applied for the synthesis of 1, 4-dihydropyridine, 4H-chromene, and 2 3-dihydro quinazoline derivatives under optimizing the reaction states. Based on model reactions that are provided in Tables 2, 3 and 4, a wide range of different derivatives of the desired multicomponent reactions were prepared with high yield.

\section{Reusibility study of catalyst of g- $\mathrm{C}_{3} \mathrm{~N}_{4} @ L$-arginine}

According to the importance of recovery and recyclability factors in green chemistry, in this section, the reusability of g- $\mathrm{C}_{3} \mathrm{~N}_{4} @ \mathrm{~L}$-arginine was examined in the synthesis of 1, 3-dihydropyridine $5 \mathrm{~b}, 4 \mathrm{H}$-chromene $9 \mathrm{~b}$, and 2,3-dihydroquinazoline 13b. For this purpose, after the execution of runs 1, the catalyst of g- $\mathrm{C}_{3} \mathrm{~N}_{4} @ \mathrm{~L}$ arginine was separated from reaction media, washed with ethanol, and dried in an oven at $70^{\circ} \mathrm{C}$. Then it was applied again for the next runs. This work was repeated for five-times that obtained yields were acceptable for catalytic reactions, and although performed reaction yields were decreased at each run bit by bit, in run 5th, the observed decrement was impressive in comparison with other runs (Figure 6).

However, EDX and FT-IR spectra of g- $\mathrm{C}_{3} \mathrm{~N}_{4} @ \mathrm{~L}$-arginine were prepared after the five-times recycling. Which without changes of the primary structure exhibited in figure 7.

Mechanistic study of prepared nanocatalyst insynthesis of 1, 4-dihydropyridine, 4Hchromene, and 2, 3-dihydro quinazoline derivatives 
In schemes 2, the suitable mechanism for the formation of 1, 4-dihydropyridine, 2,3-dihydro quinazoline, and $4 \mathrm{H}$-chromenederivatives are provided, that in each of the reactions, the presence of $\mathrm{g}-\mathrm{C}_{3} \mathrm{~N}_{4} @ \mathrm{~L}$-arginine can activate the reactants and different intermediates. As can see in scheme 2(a), 1, 4-dihydropyridine derivatives can synthesize in two methods. In the first method, aldehyde and dimedone in the presence of g- $\mathrm{C}_{3} \mathrm{~N}_{4} @ \mathrm{~L}-$ arginine produce intermediate $\mathbf{I}$, and the intermediate II is formed from the reaction between ethyl acetoacetate and ammonium acetate. But in the second method, dimedone and ammonium acetate in the presence of g$\mathrm{C}_{3} \mathrm{~N}_{4} @ \mathrm{~L}$-arginine produce intermediate III, and from the reaction between ethyl acetoacetate and aldehyde is formed intermediate IV, in any case, both methods ultimately lead to product $\mathbf{V}$.

A suggested mechanism for the formation of 2, 3-dihydro quinazoline derivatives is shown in scheme 2(b). At first, isotonic anhydride reacts with ammonium acetate in the presence of $\mathrm{g}-\mathrm{C}_{3} \mathrm{~N}_{4} @ \mathrm{~L}$-arginine and produces the intermediate I, then aldehyde activates by $\mathrm{g}-\mathrm{C}_{3} \mathrm{~N}_{4} @ \mathrm{~L}$-arginine and adds to intermediate II. Finally, after removing $\mathrm{H}$, the desired product (IV) is synthesized.

In scheme 2 (c), a plausible method for synthesis of $4 \mathrm{H}$-chromenederivatives in the presence of g- $\mathrm{C}_{3} \mathrm{~N}_{4} @ \mathrm{~L}$ arginine is presented. In this mechanism, from the reaction between aldehyde and dimedone produces intermediate I, then the addition of malononitrile lead to the formation of intermediate II, that at the end, product IV is synthesized.

\section{Catalytic evaluation of designed nanocatalystcompared to other reported studies}

In tables 5,6 and 7, the functional and performance of $\mathrm{g}-\mathrm{C}_{3} \mathrm{~N}_{4} @ \mathrm{~L}$-arginine were compared to other catalysts for the synthesis of desired derivatives (1,4-dihydropyridine, $4 \mathrm{H}$-chromene, and 2,3-dihydro quinazoline derivatives). For this comparison, various parameters such as the amount of catalyst, time reaction, temperature condition, and reaction yield were applied. According to the table provided for each of the desired reaction, the advantage of the synthesized catalyst could be seen compared to other catalysts. The catalyst of $\mathrm{g}-\mathrm{C}_{3} \mathrm{~N}_{4} @ \mathrm{~L}$-arginine is a unique heterogonous nanocatalyst that can be used in a wide range of condensation reactions in addition to simple separation conditions of the reaction mixture. On the other side, this nanocatalyst's performance was exceptional in the synthesis of 1, 4-dihydropyridine, 4 Hchromene, and 2, 3dihydro quinazoline derivatives with higher yield and shorter reaction time.

\section{Experimental Section}

\section{Reagents and Apparatus}

All chemicals were purchased from Merck and Sigma-Aldrich chemical companies. Fourier Transform Infrared (FT-IR) spectra were recorded by Tensor27, Nuclear Magnetic Resonance (NMR) data were acquired on a Varian-Inova 500MHz, x-Ray Diffraction (XRD) measurements were carried out by Dron-8, Energy-dispersive Xray (EDX) spectrum was recorded on Numerix DXP-X10P, thermal gravimetric analysis (TGA) was taken by STA 504 instrument under an argon atmosphere. Field Emission Scanning Electron Microscopy (FESEM) images were prepared with TESCAN-MIRA III.

\section{Preparation of bulk g- $\mathrm{C}_{3} \mathrm{~N}_{4}$ and $\mathrm{g}-\mathrm{C}_{3} \mathrm{~N}_{4}$ nanosheets}


For the synthesis of bulk g- $\mathrm{C}_{3} \mathrm{~N}_{4}$, the melamine was heated at $550{ }^{\circ} \mathrm{C}$ temperature in a furnace at the ramp 2.5

${ }^{\circ} \mathrm{C}$ min $^{-1}$ in static air for $4 \mathrm{~h}$. A yellow powder was obtained, which was grounded with a ball mill. For the synthesis of $\mathrm{g}-\mathrm{C}_{3} \mathrm{~N}_{4}$ nanosheets, first bulk g- $\mathrm{C}_{3} \mathrm{~N}_{4}(1.0 \mathrm{~g})$ was stirred in $\mathrm{H}_{2} \mathrm{SO}_{4}(20 \mathrm{~mL})$ at $90{ }^{\circ} \mathrm{C}$ for $5 \mathrm{~h}$, then diluted with ethanol $(200 \mathrm{~mL})$ and was stirred again at room temperature for $2 \mathrm{~h}$. The resulting product was dispersed in the $100.0 \mathrm{~mL}$ of water/isopropanol (1:1) and sonicated for $6 \mathrm{~h}$. Finally, the formed suspension was centrifuged (5000 rpm) for $\mathrm{g}-\mathrm{C}_{3} \mathrm{~N}_{4}$ nanosheets separation.

\section{Preparation of $\mathrm{g}-\mathrm{C}_{3} \mathrm{~N}_{4} @ \mathrm{~L}$-arginine}

Nanosheets $\mathrm{g}-\mathrm{C}_{3} \mathrm{~N}_{4}(1.0 \mathrm{~g})$ were dispersed in dry toluene $(20.0 \mathrm{~mL})$ then, 1,3dibromopropane $(2.0 \mathrm{~mL})$ was added to the solution, and the reaction mixture was refluxed under $\mathrm{N}_{2}$ atmosphere for $24 \mathrm{~h}$. Finally, the product was filtered and was washed with ethyl acetate, and dried at room temperature. The resulting product was solved in a mixture of water and methanol (1:1) then, L-arginine ( $1 \mathrm{mmol}), \mathrm{K}_{2} \mathrm{CO}_{3}(1.0 \mathrm{mmol})$, and $\mathrm{Nal}(1.0$ $\mathrm{mmol}$ ) were added. The solution was stirred at room temperature for $24 \mathrm{~h}$; the reaction mixture was washed with water and methanol and dried at room temperature.

\section{General procedure for the synthesis of 1, 4-dihydropyridine derivatives}

A mixture of aldehyde $(1.0 \mathrm{mmol})$, ethyl acetoacetate $(1.0 \mathrm{mmol})$, dimedone $(1.0 \mathrm{mmol})$, ammonium acetate (1.0 mmol), g- $\mathrm{C}_{3} \mathrm{~N}_{4} @ \mathrm{~L}$-arginine $(20.0 \mathrm{mg})$, and ethanol $(2.0 \mathrm{~mL})$ was added in a round bottom flask and refluxed at $70{ }^{\circ} \mathrm{C}$. When the reaction was completed (was monitored by TLC), the catalyst was separated by filtration.

\section{General procedure for the synthesis of 2,3-dihydro quinazoline derivatives}

In a round bottom flask, aldehyde $(1.0 \mathrm{mmol})$, isotonic anhydride $(1.0 \mathrm{mmol})$, ammonium acetate $(2.0 \mathrm{mmol})$, and g- $\mathrm{C}_{3} \mathrm{~N}_{4} @ \mathrm{~L}$-arginine $(20.0 \mathrm{mg})$ were added and refluxed in ethanol $(2.0 \mathrm{~mL})$ at $70^{\circ} \mathrm{C}$. After completion of the reaction (was monitored by TLC), the catalyst was removed by filtration and washed with ethanol.

\section{General procedure for the synthesis of $4 \nrightarrow$ chromene derivatives}

In a usual experiment, in a round bottom flask were added aldehyde $(1.0 \mathrm{mmol})$, dimedone $(1.0 \mathrm{mmol})$, malononitrile (1.0 mmol), g- $\mathrm{C}_{3} \mathrm{~N}_{4} @ \mathrm{~L}$-arginine $(20.0 \mathrm{mg})$, and ethanol $(2.0 \mathrm{~mL})$. Then refluxed at $70{ }^{\circ} \mathrm{C}$ until the reaction was completed (was monitored by TLC), at last, catalyst separation and crystallization was performed as above.

\section{Conclusions}

In summary, we prepared a heterogeneous nanocatalyst of g- $\mathrm{C}_{3} \mathrm{~N}_{4} @$ @-arginine. Also, nanocatalyst prepared for the synthesis of 1, 4- dihydropyridine, $4 \mathrm{H}$-chromene, and 2, 3-dihydro quinazoline derivatives were used, which are important products in pharmacologically actives compounds. This nanocatalyst's most significant advantages consist of reusability, simple separation of the reaction mixture, use for a broad range of condensation reactions with high efficiency, and short reaction time. On the other hand, the use of an easy and 
convenient method for the preparation of nanocatalyst has led to the superiority of this catalyst over other reported catalysts.

\section{Selected Spectral Data}

Ethyl 2,7,7-trimethyl-5-oxo-4-(4-hydroxylphenyl)-1,4,5,6,7,8-hexahydroquinoline-3-carboxylate (5c)

FTIR $\left(\mathrm{KBr}, \mathrm{cm}^{-1}\right): 3270,3194,3071,2957,1678,1645,1481,1377,1214 \mathrm{~cm}^{-1} .{ }^{1} \mathrm{H}$ NMR (500 MHz, DMSO): $\delta \mathrm{H}$ $(\mathrm{ppm})=0.85\left(\mathrm{~s}, 3 \mathrm{H}, \mathrm{CH}_{3}\right), 1.0\left(\mathrm{~s}, 3 \mathrm{H}, \mathrm{CH}_{3}\right), 1.13\left(\mathrm{t}, 3 \mathrm{H}, \mathrm{CH}_{3}\right), 1.9-2.41(\mathrm{~m}, 4 \mathrm{H}, 2 \mathrm{CH} 2), 2.25(\mathrm{~s}, 3 \mathrm{H}, \mathrm{CH} 3), 3.95-$ 3.99(q, 2H, OCH2), 4.73(s, 1H, Ar-CH), 6.54(d, 2H, Ar-H), 6.93(d, 2H, Ar-H), 8.95(s, 1H, NH), 9.01(s,1H, OH). Ethyl 1,4,7,8-tetrahydro-2,7,7-trimethyl-4-(4-nitrophenyl)-5(6H)-oxoquinoline-3-carboxylate (5d)

FTIR $\left(\mathrm{KBr}, \mathrm{cm}^{-1}\right): 3276,3210,3076,2969,2902,1703,1641,1530,1379 \mathrm{~cm}^{-1} .{ }^{1} \mathrm{H}$ NMR (500 MHz, DMSO): $\delta \mathrm{H}$ $(\mathrm{ppm})=0.83\left(\mathrm{~s}, 3 \mathrm{H}, \mathrm{CH}_{3}\right), 1.01\left(\mathrm{~s}, 3 \mathrm{H}, \mathrm{CH}_{3}\right), 1.11\left(\mathrm{t}, 3 \mathrm{H}, \mathrm{CH}_{3}\right), 1.96-2.46(\mathrm{~m}, 4 \mathrm{H}, 2 \mathrm{CH} 2), 2.31(\mathrm{~s}, 3 \mathrm{H}, \mathrm{CH} 3), 3.93-$ 4.0(m, 2H, OCH2), 4.97(s, 1H, Ar-CH), 7.5-7.61 (m, 4H, Ar-H), 7.97(s, 1H, NH), 9.23(s,1H, OH).

2-amino-4-(4-nitrophenyl)-7,7-dimethyl-5-oxo-5,6,7,8-tetrahydro-4Hchromene-3-carbonitrile (9c)

FTIR $\left(\mathrm{KBr}, \mathrm{cm}^{-1}\right)$ : 3403, 3312, 3170, 2969, 2881,2181, 1668, 1626, 1517, 1345, $856 \mathrm{~cm}^{-1} .{ }^{1} \mathrm{H}$ NMR $(500 \mathrm{MHz}$, DMSO): $\delta \mathrm{H}(\mathrm{ppm})=0.95(\mathrm{~s}, 3 \mathrm{H}, \mathrm{CH} 3), 1.04(\mathrm{~s}, 3 \mathrm{H}, \mathrm{CH} 3), 2.09-2.53(\mathrm{~m}, 4 \mathrm{H}, 2 \mathrm{CH} 2), 4.36(\mathrm{~s}, 1 \mathrm{H}, \mathrm{CH}), 7.1(\mathrm{~s}, 2 \mathrm{H}$, $\mathrm{NH} 2), 7.43-8.17(\mathrm{~m}, 4 \mathrm{H}, \mathrm{Ar}-\mathrm{H})$.

\section{2-phenyl-2, 3-dihydro-4(1 H)-quinazolinone (13a)}

FTIR $\left(\mathrm{KBr}, \mathrm{cm}^{-1}\right): 3300,3176,2981,1651,1610,1507,1440,1385,745 \mathrm{~cm}^{-1} .{ }^{1} \mathrm{H}$ NMR (500 MHz, DMSO): $\delta \mathrm{H}$ $(\mathrm{ppm})=5.75(\mathrm{~s}, 1 \mathrm{H}, \mathrm{CH}), 6.67(\mathrm{t}, 1 \mathrm{H}, \mathrm{Ar}-\mathrm{H}), 6.74(\mathrm{~d}, 1 \mathrm{H}, \mathrm{Ar}-\mathrm{H}), 7,1(\mathrm{~s}, 1 \mathrm{H}, \mathrm{NH}), 7.23(\mathrm{t}, 1 \mathrm{H}, \mathrm{Ar}-\mathrm{H}), 7.34(\mathrm{t}, 1 \mathrm{H}, \mathrm{Ar}-\mathrm{H})$, 7.38(t, 1H, Ar-H), 7.49(d, 1H, Ar-H), 7.60(d, 1H, Ar-H), 8.27(s, 1H, CONH).

\section{2-(4-chloro-phenyl)-2, 3-dihydro-1 Hquinazoline-4-one (13b)}

$\operatorname{FTIR}\left(\mathrm{KBr}, \mathrm{cm}^{-1}\right)$ : 3305, 3184, 3062, 1654, 1606, 1431, 1090, $749 \mathrm{~cm}^{-1} .{ }^{1} \mathrm{H}$ NMR (500 MHz, DMSO): $\delta \mathrm{H}$ (ppm) $=5.77(\mathrm{~s}, 1 \mathrm{H}, \mathrm{CH}), 6.68(\mathrm{t}, 1 \mathrm{H}, \mathrm{Ar}-\mathrm{H}), 6.74(\mathrm{~d}, 1 \mathrm{H}, \mathrm{Ar}-\mathrm{H}), 7,1(\mathrm{~s}, 1 \mathrm{H}, \mathrm{NH}), 7.24(\mathrm{t}, 1 \mathrm{H}, \mathrm{Ar}-\mathrm{H}), 7.45(\mathrm{~d}, 1 \mathrm{H}, \mathrm{Ar}-\mathrm{H}), 7.50(\mathrm{~d}$, $1 \mathrm{H}, \mathrm{Ar}-\mathrm{H}), 7.61(\mathrm{~d}, 1 \mathrm{H}, \mathrm{Ar}-\mathrm{H}), 8.27(\mathrm{~s}, 1 \mathrm{H}, \mathrm{CONH})$.

\section{Declarations}

\section{AUTHOR INFORMATION}

Corresponding Author

ghafuri@iust.ac.ir, Tel: +98-(0)21- 77240 540, Fax: +98- (0)21-77491204

\section{ACKNOWLEDGMENTS}

We are grateful for the financial support from The Research Council of Iran University of Science and Technology (IUST), Tehran, Iran. 


\section{References}

1. Rashidizadeh, A., Ghafuri, H., Zand, E., Goodarzi, N. \& H. R. \& Graphitic carbon nitride nanosheets covalently functionalized with biocompatible vitamin B1: synthesis, characterization, and its superior performance for synthesis of quinoxalines. ACS omega. 4, 12544-12554 (2019).

2. Rahmati, M. \& Ghafuri, H. Catalytic Strecker reaction: gC $3 \mathrm{~N}$ 4-anchored sulfonic acid organocatalyst for the synthesis of a-aminonitriles. Research on Chemical Intermediates,1-14(2021).

3. Zhang, Z., Liu, K., Feng, Z., Bao, Y. \& Dong, B. Hierarchical sheet-on-sheet Znln 2 S 4/gC 3 N 4 heterostructure with highly efficient photocatalytic $\mathrm{H} 2$ production based on photoinduced interfacial charge transfer. Scientific reports. 6, 1-10 (2016).

4. Kumar, R., Barakat, M. \& Alseroury, F. Oxidized gC $3 \mathrm{~N}$ 4/polyaniline nanofiber composite for the selective removal of hexavalent chromium. Scientific reports. 7, 1-11 (2017).

5. Dong, G., Zhang, Y., Pan, Q. \& Qiu, J. A fantastic graphitic carbon nitride (g-C3N4) material: electronic structure, photocatalytic and photoelectronic properties. Journal of Photochemistry and Photobiology C: Photochemistry Reviews. 20, 33-50 (2014).

6. Wu, Y. et al. Electrocatalytic performances of gC $3 \mathrm{~N} 4$-LaNiO 3 composite as bi-functional catalysts for lithium-oxygen batteries. Scientific reports. 6, 1-8 (2016).

7. Han, H. et al. Cu and boron doped carbon nitride for highly selective oxidation of toluene to benzaldehyde. Molecules. 20, 12686-12697 (2015).

8. Davarpanah, J., Ghahremani, M. \& Najafi, O. Synthesis of 1, 4-dihydropyridine and polyhydroquinoline derivatives via Hantzsch reaction using nicotinic acid as a green and reusable catalyst. Journal of Molecular Structure. 1177, 525-535 (2019).

9. Kusampally, U., Dhachapally, N., Kola, R. \& Kamatala, C. R. Zeolite anchored Zr-ZSM-5 as an eco-friendly, green, and reusable catalyst in Hantzsch synthesis of dihydropyridine derivatives. Materials Chemistry and Physics. 242, 122497 (2020).

10. Alponti, L. H., Picinini, M., Urquieta-Gonzalez, E. A. \& Corrêa, A. G. USY-zeolite catalyzed synthesis of 1, 4dihydropyridines under microwave irradiation: structure and recycling of the catalyst. Journal of Molecular Structure. 1227, 129430 (2021).

11. Das, D. Multicomponent Reactions in Organic Synthesis Using Copper-Based Nanocatalysts. ChemistrySelect 1, 1959-1980(2016).

12. Domling, A., Wang, W. \& Wang, K. Chemistry and biology of multicomponent reactions. Chemical reviews. 112, 3083-3135 (2012).

13. Khazaei, A., Moosavi-Zare, A. R., Mohammadi, Z., Khakyzadeh, V. \& Afsar, J. Nano-TiO2 as an Efficient Catalyst for Tandem Knoevenagel-Michael-Cyclocondensation Reaction of Dimedone with Aromatic Aldehydes and Ammonium Acetate or Aromatic Amines under Solvent-free Conditions. Journal of the Chinese Chemical Society. 63, 165-170 (2016).

14. Aute, D., Kshirsagar, A., Uphade, B. \& Gadhave, A. Aluminized polyborate-catalysed green and efficient synthesis of polyhydroquinolines under solvent-free conditions. Research on Chemical Intermediates. 46, 3491-3508 (2020). 
15. Zhang, Q., Ma, X. M., Wei, H. X., Zhao, X. \& Luo, J. Covalently anchored tertiary amine functionalized ionic liquid on silica coated nano-Fe 304 as a novel, efficient and magnetically recoverable catalyst for the unsymmetrical Hantzsch reaction and Knoevenagel condensation. RSC advances. 7, 53861-53870 (2017).

16. Kiyani, H. \& Ghorbani, F. (Springer, 2015).

17. Yü, S. J., Wu, S., Zhao, X. M. \& Lü, C. W. Green and efficient synthesis of acridine-1, 8-diones and hexahydroquinolines via a KH 2 PO 4 catalyzed Hantzsch-type reaction in aqueous ethanol. Research on Chemical Intermediates. 43, 3121-3130 (2017).

18. Zhang, Q., Wei, H., Li, J., Zhao, X. \& Luo, J. One-pot synthesis of benzopyrans catalyzed by silica supported dual acidic ionic liquid under solvent-free conditions. Heterocycl. Commun. 23, 411-414 (2017).

19. Lu, J., Fu, X., Zhang, G. \& Wang, C. $\beta$-Cyclodextrin as an efficient catalyst for the one-pot synthesis of tetrahydrobenzo [b] pyran derivatives in water. Research on Chemical Intermediates. 42, 417-424 (2016).

20. Malviya, J., Kala, S., Sharma, L. \& Singh, R. Efficient Three-Component One-Pot Synthesis of 4 H-Pyrans. Russian Journal of Organic Chemistry. 55, 686-693 (2019).

21. Mirjalili, B. B. F., Zaghaghi, Z. \& Monfared, A. Synthesis of 2, 3-dihydroquinazolin-4 (1H)-ones in the presence of Fe304@ nano-cellulose-OPO3H as a bio-based magnetic nanocatalyst. Journal of the Chinese Chemical Society. 67, 197-201 (2020).

22. Rao, A. D. et al. Sulfonic acid functionalized Wang resin (Wang-OSO3H) as polymeric acidic catalyst for the eco-friendly synthesis of 2, 3-dihydroquinazolin-4 (1H)-ones. Tetrahedron letters. 56, 4714-4717 (2015).

23. Pan, S. et al. MCM-41@ Schiff base-Co (OAc) 2 as an efficient catalyst for the synthesis of pyran derivatives. Research on Chemical Intermediates. 46, 1353-1371 (2020).

24. Hong, M. \& Cai, C. Ytterbium (III) bis (perfluorooctanesulfonyl) imide catalyzed one-pot synthesis of tetrahydrobenzo [b] pyrans in fluorous biphase system. Journal of Chemical Research. 34, 568-570 (2010).

25. Tamoradi, T., Ghadermazi, M. \& Ghorbani-Choghamarani, A. Synthesis of polyhydroquinoline, 2, 3dihydroquinazolin-4 $(1 \mathrm{H})$-one, sulfide and sulfoxide derivatives catalyzed by new copper complex supported on MCM-41. Catal. Lett. 148, 857-872 (2018).

26. Mekala, R. et al. Efficient synthesis of 2, 3-dihydroquinazolin-4 (1H)-ones catalyzed by titanium silicon oxide nanopowder in aqueous media. Synth. Commun. 47, 121-130 (2017).

27. Khan, A. A., Mitra, K., Mandal, A., Baildya, N. \& Mondal, M. A. Yttrium nitrate catalyzed synthesis, photophysical study, and TD-DFT calculation of 2, 3-dihydroquinazolin-4 (1H)-ones. Heteroat. Chem. 28, e21379 (2017).

28. Guo, X., Duan, J., Li, C., Zhang, Z. \& Wang, W. Highly efficient Z-scheme gC 3 N 4/ZnO photocatalysts constructed by co-melting-recrystallizing mixed precursors for wastewater treatment. Journal of Materials Science. 55, 2018-2031 (2020).

29. Yang, X., Tang, B., Wu, T. \& Cao, X. g-C3N4/TiO2 composite photocatalyst and its application to asphalt for NO removal. Journal of Materials in Civil Engineering. 31, 04019141 (2019). 
30. Li, X. et al. Synergistic effect of efficient adsorption g-C3N4/ZnO composite for photocatalytic property. Journal of Physics and Chemistry of Solids. 75, 441-446 (2014).

31. Rahmati, M., Ghafuri, H., Ghanbari, N. \& Tajik, Z. 1, 4 Butanesultone Functionalized Graphitic Carbon Nitride: Efficient Catalysts for the One-Pot Synthesis of 1, 4-Dihydropyridine and Polyhydroquinoline Derivative through Hantzsch Reaction. Polycyclic Aromatic Compounds,1-17(2020).

32. Maleki, A., Eskandarpour, V., Rahimi, J. \& Hamidi, N. Cellulose matrix embedded copper decorated magnetic bionanocomposite as a green catalyst in the synthesis of dihydropyridines and polyhydroquinolines. Carbohydrate polymers. 208, 251-260 (2019).

33. Brahmachari, G., Laskar, S. \& Banerjee, B. Eco-friendly, One-Pot Multicomponent Synthesis of Pyran Annulated Heterocyclic Scaffolds at Room Temperature Using Ammonium or Sodium Formate as Nontoxic Catalyst. Journal of Heterocyclic Chemistry. 51, E303-E308 (2014).

34. Qareaghaj, O. H., Mashkouri, S., Naimi-Jamal, M. R. \& Kaupp, G. Ball milling for the quantitative and specific solvent-free Knoevenagel condensation + Michael addition cascade in the synthesis of various 2amino-4-aryl-3-cyano-4 H-chromenes without heating. RSC Advances. 4, 48191-48201 (2014).

35. Dekamin, M. G. \& Eslami, M. Highly efficient organocatalytic synthesis of diverse and densely functionalized 2-amino-3-cyano-4 H-pyrans under mechanochemical ball milling. Green Chem. 16, 49144921 (2014).

36. Ghafuri, H., Goodarzi, N., Rashidizadeh, A. \& Fard, M. A. D. ompg-C 3 N 4/SO 3 H: an efficient and recyclable organocatalyst for the facile synthesis of 2, 3-dihydroquinazolin-4 $(1 \mathrm{H})$-ones. Research on Chemical Intermediates. 45, 5027-5043 (2019).

37. Pourhasan-Kisomi, R., Shirini, F. \& Golshekan, M. Introduction of organic/inorganic Fe304@ MCM-41@ Zrpiperazine magnetite nanocatalyst for the promotion of the synthesis of tetrahydro-4H-chromene and pyrano [2, 3-d] pyrimidinone derivatives. Appl. Organomet. Chem. 32, e4371 (2018).

38. Zhang, Q., Gao, Y. H., Qin, S. L. \& Wei, H. X. Facile One-Pot Synthesis of Amidoalkyl Naphthols and Benzopyrans Using Magnetic Nanoparticle-Supported Acidic lonic Liquid as a Highly Efficient and Reusable Catalyst. Catalysts. 7, 351 (2017).

39. Khodabakhshi, M. R., Kiamehr, M. \& Karimian, R. Efficient One-Pot Synthesis of 1, 4-Dihydropyridine and Polyhydroquinoline Derivatives Using Sulfanilic Acid-Functionalized Boehmite Nano-Particles as an Organic-Inorganic Hybrid Catalyst.Polycyclic Aromatic Compounds,1-15(2021).

40. Karhale, S., Bhenki, C., Rashinkar, G. \& Helavi, V. Covalently anchored sulfamic acid on cellulose as heterogeneous solid acid catalyst for the synthesis of structurally symmetrical and unsymmetrical 1, 4dihydropyridine derivatives. New Journal of Chemistry. 41, 5133-5141 (2017).

41. Tekale, S. U., Munde, S. B., Kauthale, S. S. \& Pawar, R. P. An Efficient, Convenient, and Solvent-Free Synthesis of 2, 3-Dihydroquinazolin-4 $(1 \mathrm{H})$-ones Using Montmorillonite-KSF Clay as a Heterogeneous Catalyst. Organic Preparations and Procedures International. 50, 314-322 (2018).

\section{Tables}


Table 1

Optimization of different parameters due to considering the model reaction (a).

\begin{tabular}{|c|c|c|c|c|c|c|c|c|}
\hline Entry & catalyst & $\begin{array}{l}\text { Catalyst } \\
\text { Loading } \\
\text { (mg) }\end{array}$ & solvent & Time(min) & $\begin{array}{l}\text { condition } \\
\text { /temperature }\end{array}$ & $\begin{array}{l}\text { Reaction } \\
\text { (1) } \\
\text { Yield (\%) }\end{array}$ & $\begin{array}{l}\text { Reaction } \\
\text { (2) } \\
\text { Yield (\%) }\end{array}$ & $\begin{array}{l}\text { Reaction } \\
\text { (3) } \\
\text { Yield (\%) }\end{array}$ \\
\hline 1 & - & - & EtOH & 60 & r.t & - & - & - \\
\hline 2 & - & - & EtOH & 60 & reflux & - & - & - \\
\hline 3 & $\begin{array}{l}\mathrm{g}_{-} \\
\mathrm{C}_{3} \mathrm{~N}_{4} @ \mathrm{~L}- \\
\text { arginine }\end{array}$ & 1.00 & $\mathrm{EtOH}$ & 15 & reflux & 53 & 60 & 57 \\
\hline 4 & $\begin{array}{l}\mathrm{g}_{-} \\
\mathrm{C}_{3} \mathrm{~N}_{4} @ \mathrm{~L}- \\
\text { arginine }\end{array}$ & 10.00 & $\mathrm{EtOH}$ & 15 & reflux & 85 & 90 & 87 \\
\hline 5 & $\begin{array}{l}\mathrm{g}- \\
\mathrm{C}_{3} \mathrm{~N}_{4} @ \mathrm{~L}- \\
\text { arginine }\end{array}$ & 20.00 & EtOH & 15 & reflux & 94 & 97 & 96 \\
\hline 6 & $\begin{array}{l}\mathrm{g}- \\
\mathrm{C}_{3} \mathrm{~N}_{4} @ \mathrm{~L}- \\
\text { arginine }\end{array}$ & 30.00 & EtOH & 15 & reflux & 95 & 98 & 96 \\
\hline 7 & $\begin{array}{l}\mathrm{g}_{-} \\
\mathrm{C}_{3} \mathrm{~N}_{4} @ \mathrm{~L}- \\
\text { arginine }\end{array}$ & 20.00 & EtOH & 10 & reflux & 89 & 97 & 93 \\
\hline 8 & $\begin{array}{l}\mathrm{g}_{-} \\
\mathrm{C}_{3} \mathrm{~N}_{4} @ \mathrm{~L}- \\
\text { arginine }\end{array}$ & 20.00 & EtOH & 20 & reflux & 95 & 98 & 93 \\
\hline 9 & $\begin{array}{l}\mathrm{g}_{-} \\
\mathrm{C}_{3} \mathrm{~N}_{4} @ \mathrm{~L}- \\
\text { arginine }\end{array}$ & 20.00 & $\mathrm{EtOH}$ & 30 & reflux & 96 & 98 & 94 \\
\hline 10 & $\begin{array}{l}\mathrm{g}_{-} \\
\mathrm{C}_{3} \mathrm{~N}_{4} @ \mathrm{~L}- \\
\text { arginine }\end{array}$ & 20.00 & $\mathrm{CH}_{2} \mathrm{Cl}_{2}$ & 15 & reflux & 54 & 67 & 60 \\
\hline 11 & $\begin{array}{l}\mathrm{g}^{-} \\
\mathrm{C}_{3} \mathrm{~N}_{4} @ \mathrm{~L}- \\
\text { arginine }\end{array}$ & 20.00 & DMF & 15 & reflux & 52 & 56 & 55 \\
\hline 12 & $\begin{array}{l}\text { g- } \\
\mathrm{C}_{3} \mathrm{~N}_{4} @ L- \\
\text { arginine }\end{array}$ & 20.00 & $\mathrm{H}_{2} \mathrm{O}$ & 15 & reflux & 75 & 78 & 77 \\
\hline
\end{tabular}

(a) Model reaction (1): 4-chlorobenzaldehyde (1 mmol), ethyl acetoacetate $(1 \mathrm{mmol})$, dimedone $(1 \mathrm{mmol})$, and ammonium acetate ( $1 \mathrm{mmol}$ ) for synthesis of 1, 4-dihydropyridine. Model reaction (2): 4-

chlorobenzaldehyde $(1 \mathrm{mmol})$, dimedone $(1 \mathrm{mmol})$, and malononitrile $(1 \mathrm{mmol})$ for synthesis of $4 \mathrm{H}-$ chromene. Model reaction (3): 4-chlorobenzaldehyde ( $1 \mathrm{mmol})$, isotonic anhydride ( $1 \mathrm{mmol})$, and ammonium acetate $(1 \mathrm{mmol})$ for synthesis of 2, 3-dihydroquinazoline. 


\begin{tabular}{|c|c|c|c|c|c|c|c|c|}
\hline Entry & catalyst & $\begin{array}{l}\text { Catalyst } \\
\text { Loading } \\
\text { (mg) }\end{array}$ & solvent & Time(min) & $\begin{array}{l}\text { condition } \\
\text { /temperature }\end{array}$ & $\begin{array}{l}\text { Reaction } \\
\text { (1) } \\
\text { Yield (\%) }\end{array}$ & $\begin{array}{l}\text { Reaction } \\
(2) \\
\text { Yield (\%) }\end{array}$ & $\begin{array}{l}\text { Reaction } \\
\text { (3) } \\
\text { Yield (\%) }\end{array}$ \\
\hline 13 & $\begin{array}{l}\mathrm{g}- \\
\mathrm{C}_{3} \mathrm{~N}_{4} @ \mathrm{~L}- \\
\text { arginine }\end{array}$ & 20.00 & $\mathrm{EtOH}$ & 15 & r.t & 57 & 66 & 68 \\
\hline \multicolumn{9}{|c|}{$\begin{array}{l}\text { (a) Model reaction }(1) \text { : 4-chlorobenzaldehyde }(1 \mathrm{mmol}) \text {, ethyl acetoacetate }(1 \mathrm{mmol}) \text {, dimedone }(1 \mathrm{mmol}) \text {, and } \\
\text { ammonium acetate }(1 \mathrm{mmol}) \text { for synthesis of } 1,4 \text {-dihydropyridine. Model reaction }(2): 4- \\
\text { chlorobenzaldehyde }(1 \mathrm{mmol}) \text {, dimedone }(1 \mathrm{mmol}) \text {, and malononitrile }(1 \mathrm{mmol}) \text { for synthesis of } 4 \mathrm{H}- \\
\text { chromene. Model reaction }(3): 4 \text {-chlorobenzaldehyde }(1 \mathrm{mmol}) \text {, isotonic anhydride }(1 \mathrm{mmol}) \text {, and } \\
\text { ammonium acetate }(1 \mathrm{mmol}) \text { for synthesis of } 2 \text {, 3-dihydroquinazoline. }\end{array}$} \\
\hline
\end{tabular}

Table2. The synthesis of 1, 4-dihydropyridine derivatives by g- $\mathrm{C}_{3} \mathrm{~N}_{4} @ \mathrm{~L}$-arginine.

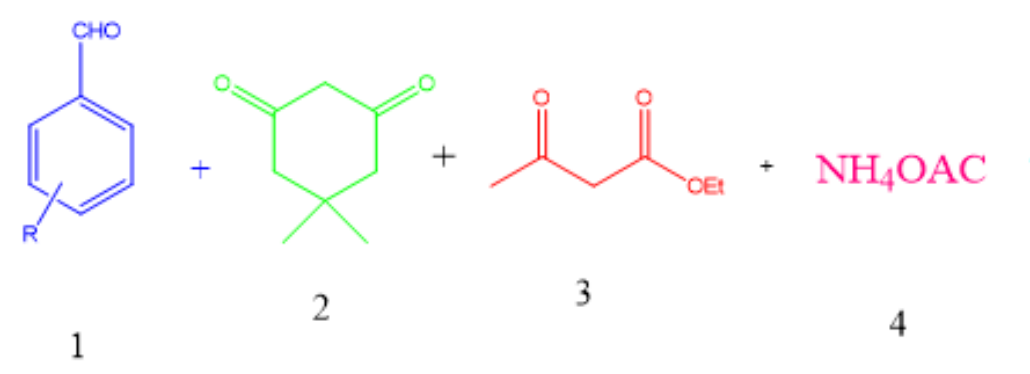

g- $\mathrm{C}_{3} \mathrm{~N}_{4} @ \mathrm{~L}$-arginine

Ethanol, reflux

\begin{tabular}{|lllllll|}
\hline \multicolumn{1}{|c|}{} \\
\hline Entry & $\mathrm{R}$ & Product & Time (min) & $\mathrm{Mp}\left({ }^{\circ} \mathrm{C}\right)$ & $\mathrm{Mp}\left({ }^{\circ} \mathrm{C}\right.$, ref. $)$ & Yeild (\%) \\
\hline $\mathbf{1}$ & $\mathrm{H}$ & $5 \mathrm{a}$ & 10 & $217-219$ & $218-220^{17}$ & 95 \\
\hline $\mathbf{2}$ & $4-\mathrm{Cl}$ & $5 \mathrm{~b}$ & 15 & $240-242$ & $241-243^{17}$ & 94 \\
\hline $\mathbf{3}$ & $4-\mathrm{OH}$ & $5 \mathrm{c}$ & 20 & $230-232$ & $231-232^{14}$ & 89 \\
\hline $\mathbf{4}$ & $4-\mathrm{NO}_{2}$ & $5 \mathrm{~d}$ & 15 & $239-241$ & $240-242^{14}$ & 90 \\
\hline $\mathbf{5}$ & $4-\mathrm{Me}$ & $5 \mathrm{e}$ & 25 & $254-256$ & $250^{32}$ & 87 \\
\hline
\end{tabular}

Table3. Synthesis of $4 H$ chromene derivatives by g- $\mathrm{C}_{3} \mathrm{~N}_{4} @ \mathrm{~L}$-arginine. 


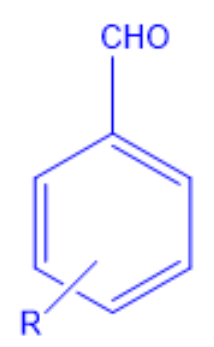

6

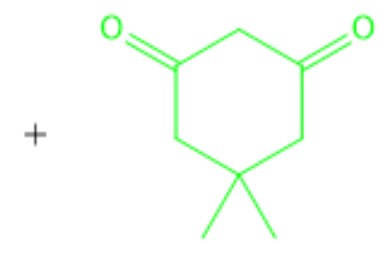

7

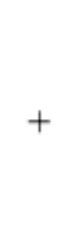

7

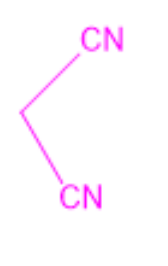

g- $\mathrm{C}_{3} \mathrm{~N}_{4} @$ L-arginine

Ethanol, reflux

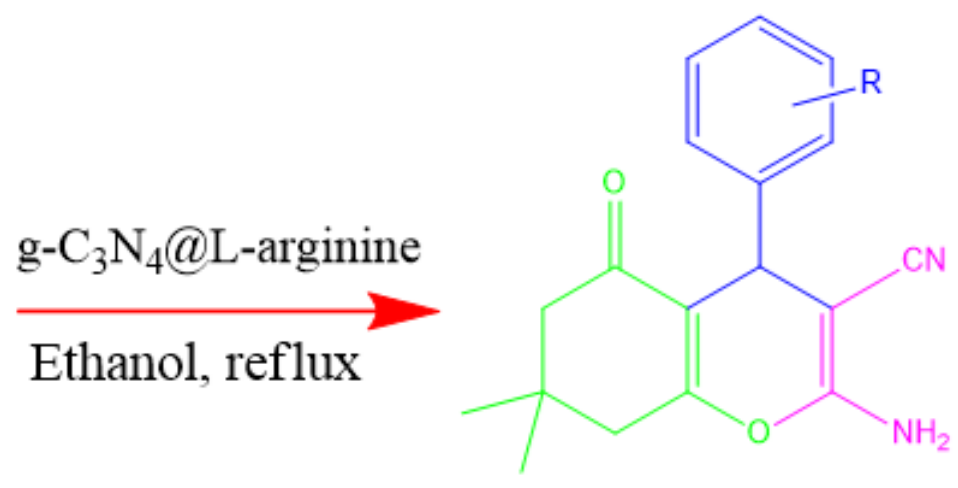

8

9a-9j

\begin{tabular}{|lllllll|}
\hline Entry & $\mathbf{R}$ & Product & Time (min) & Mp $\left({ }^{\circ} \mathrm{C}\right)$ & Mp $\left({ }^{\circ} \mathrm{C}\right.$, ref. $)$ & Yeild (\%) \\
\hline $\mathbf{1}$ & $\mathrm{H}$ & $9 \mathrm{a}$ & 7 & $228-229$ & $225-228^{33}$ & 95 \\
\hline $\mathbf{2}$ & $4-\mathrm{Cl}$ & $9 \mathrm{~b}$ & 10 & $210-212$ & $211-213^{33}$ & 97 \\
\hline $\mathbf{3}$ & $4-\mathrm{NO}_{2}$ & $9 \mathrm{c}$ & 15 & $178-179$ & $177-179^{34}$ & 88 \\
\hline $\mathbf{4}$ & $2,4-\mathrm{Cl}$ & $9 \mathrm{~d}$ & 10 & $118-120$ & $115-117^{24}$ & 95 \\
\hline $\mathbf{5}$ & $4-\mathrm{OH}$ & $9 \mathrm{e}$ & 20 & $206-208$ & $208-210^{24}$ & 93 \\
\hline $\mathbf{6}$ & $4-\mathrm{Me}$ & $9 \mathrm{f}$ & 30 & $217-220$ & $220-221^{35}$ & 91 \\
\hline $\mathbf{7}$ & $3-\mathrm{NO}{ }_{2}$ & $9 \mathrm{~g}$ & 20 & $206-207$ & $206-209^{34}$ & 93 \\
\hline $\mathbf{8}$ & $2-\mathrm{Cl}$ & $9 \mathrm{~h}$ & 15 & $213-214$ & $211-213^{35}$ & 96 \\
\hline $\mathbf{1 0}$ & $4-\mathrm{CN}$ & $9 \mathrm{i}$ & 25 & $184-187$ & $184-186^{35}$ & 89 \\
\hline
\end{tabular}

Table4. The synthesis of 2,3-dihydroquinazoline derivatives by g- $\mathrm{C}_{3} \mathrm{~N}_{4} @ \mathrm{~L}$-arginine.<smiles>O=Cc1ccccc1</smiles>

10<smiles>O=c1[nH]c2ccccc2c(=O)o1</smiles>

11
$\mathrm{NH}_{4} \mathrm{OAC}$ 12

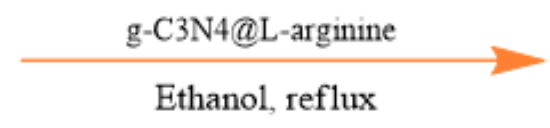
Ethanol, reflux<smiles>O=C1NC(c2ccccc2)Nc2ccccc21</smiles>

13a-13j 


\begin{tabular}{|c|c|c|c|c|c|c|}
\hline Entry & $\mathbf{R}$ & Product & $\begin{array}{l}\text { Time } \\
\text { (min) }\end{array}$ & $\mathrm{Mp}\left({ }^{\circ} \mathrm{C}\right)$ & $\mathrm{MP}\left({ }^{\circ} \mathrm{C}\right.$, ref.) & Yield \\
\hline 1 & $\mathrm{H}$ & $13 a$ & 15 & $207-210$ & $208-210^{21}$ & 90 \\
\hline 2 & $4-\mathrm{Cl}$ & $13 b$ & 15 & $203-206$ & $203-206^{36}$ & 96 \\
\hline 3 & $\begin{array}{l}3- \\
\mathrm{NO}_{2}\end{array}$ & $13 c$ & 30 & $192-193$ & $190-193^{21}$ & 89 \\
\hline 4 & $\begin{array}{l}\text { 4- } \\
\mathrm{OH}\end{array}$ & $13 d$ & 25 & $213-215$ & $213-215^{36}$ & 87 \\
\hline 5 & $2-\mathrm{Cl}$ & $13 e$ & 15 & $205-206$ & $206-208^{22}$ & 95 \\
\hline 6 & $\begin{array}{l}\text { 4- } \\
\mathrm{Me}\end{array}$ & $13 f$ & 25 & $200-201$ & $198-201^{22}$ & 86 \\
\hline 7 & $\stackrel{4-}{\mathrm{NO}_{2}}$ & $13 g$ & 20 & $201-202$ & $200-202^{36}$ & 90 \\
\hline 8 & $\begin{array}{l}\text { 4- } \\
\text { OMe }\end{array}$ & $13 \mathrm{~h}$ & 25 & $180-182$ & $178-182^{36}$ & 87 \\
\hline 9 & $\begin{array}{l}2,4- \\
\mathrm{Cl}\end{array}$ & $13 i$ & 35 & $163-166$ & $165-169^{21}$ & 94 \\
\hline 10 & $\begin{array}{l}3- \\
\mathrm{OH}\end{array}$ & $13 j$ & 30 & $212-216$ & $215-217^{36}$ & 89 \\
\hline
\end{tabular}

Table5. Evaluation of catalytic activity of g- $\mathrm{C}_{3} \mathrm{~N}_{4} @ \mathrm{~L}$-arginine with other reported studies in synthesis of $4 \mathrm{H}$ chromene derivatives ${ }^{(b)}$.

\begin{tabular}{|c|c|c|c|c|c|}
\hline Entry & Catalyst & $\begin{array}{l}\text { Solvent/Temperature } \\
\text { condition }\end{array}$ & Time(min) & $\begin{array}{l}\text { Chromene } \\
\text { Yield (\%) }\end{array}$ & Ref \\
\hline 1 & $\begin{array}{l}\mathrm{Fe}_{3} \mathrm{O}_{4} @ M C M-41 @ Z r-p i p e r a z i n e- \\
\text { MNPs }\end{array}$ & $\mathrm{EtOH} / \mathrm{H}_{2} \mathrm{O} / 75^{\circ} \mathrm{C}$ & 40 & 74 & 37 \\
\hline 2 & AIL@MNP & Solvent-free $/ 90^{\circ} \mathrm{C}$ & 25 & 89 & 38 \\
\hline 3 & MCM-41@Schiff base-Co(OAC) $)_{2}$ & $\mathrm{H}_{2} \mathrm{O} / 50^{\circ} \mathrm{C}$ & 180 & 94 & 23 \\
\hline 4 & $\mathrm{Yb}\left(\mathrm{NPf}_{2}\right)_{3}$ & $\mathrm{EtOH} / 80^{\circ} \mathrm{C}$ & 240 & 91 & 24 \\
\hline 5 & g- $\mathrm{C}_{3} \mathrm{~N}_{4} @ \mathrm{~L}$-arginine & EtOH/reflux & 7 & 95 & $\begin{array}{l}\text { This } \\
\text { work }\end{array}$ \\
\hline
\end{tabular}

(b) Reaction conditions: benzaldehyde (1 mmol), dimedone (1 mmol), malononitrile (1.5 mmol), g- $\mathrm{C}_{3} \mathrm{~N}_{4} @ \mathrm{~L}-$ arginine catalyst $(20.00 \mathrm{mg})$, and ethanol $(7 \mathrm{~mL})$ under reflux. 
Table 6. Evaluation of catalytic activity of g- $\mathrm{C}_{3} \mathrm{~N}_{4} @ \mathrm{~L}$-arginine with other reported studies in synthesis of 1, 4dihydropyridine derivatives ${ }^{(\mathrm{c})}$.

\begin{tabular}{|c|c|c|c|c|c|}
\hline Entry & Catalyst & $\begin{array}{l}\text { Solvent/Temperature } \\
\text { condition }\end{array}$ & $\begin{array}{l}\text { Time } \\
(\min )\end{array}$ & $\begin{array}{l}\text { Hanztsch } \\
\text { Yield (\%) }\end{array}$ & Ref \\
\hline 1 & $\begin{array}{l}\mathrm{BNPs} @ \mathrm{Si}\left(\mathrm{CH}_{2}\right)_{3} @ \mathrm{NH} \\
\mathrm{SO}_{3} \mathrm{H}\end{array}$ & EtOH/reflux & 25 & 95 & 39 \\
\hline 2 & Aluminized polyborate & Solvent-free $/ 100^{\circ} \mathrm{C}$ & 15 & 94 & 14 \\
\hline 3 & Cell-Pr-NHSO ${ }_{3} \mathrm{H}$ & EtOH/reflux & 45 & 91 & 40 \\
\hline 4 & MCM-41@serine@Cu(II) & $\mathrm{EtOH} / 80^{\circ} \mathrm{C}$ & 170 & 96 & 25 \\
\hline 5 & g- $\mathrm{C}_{3} \mathrm{~N}_{4} @ \mathrm{~L}$-arginine & EtOH/reflux & 10 & 95 & $\begin{array}{l}\text { This } \\
\text { work }\end{array}$ \\
\hline
\end{tabular}

Table 7. Evaluation of catalytic activity of g- $\mathrm{C}_{3} \mathrm{~N}_{4} @ \mathrm{~L}$-arginine with other reported studies in synthesis of 2, 3dihydro quinazoline derivatives

\begin{tabular}{|llllll|}
\hline Entry & Catalyst & $\begin{array}{l}\text { Solvent/Temperature } \\
\text { condition }\end{array}$ & Time(min) & $\begin{array}{l}\text { Quinazoline } \\
\text { Yield (\%) }\end{array}$ & Ref \\
\hline $\mathbf{1}$ & $\begin{array}{l}\text { Titanium silicon oxide nano } \\
\text { powder }\end{array}$ & $\mathrm{H}_{2} \mathrm{O} / 100^{\circ} \mathrm{C}$ & 120 & 94 & 26 \\
\hline $\mathbf{2}$ & Wang-OSO ${ }_{3} \mathrm{H}$ & $\mathrm{H}_{2} \mathrm{O} / 100^{\circ} \mathrm{C}$ & 24 & 84 & 22 \\
\hline $\mathbf{3}$ & $\mathrm{Y}\left(\mathrm{NO}_{3}\right)_{3} \cdot 6 \mathrm{H}_{2} \mathrm{O}$ & $\mathrm{CH}_{3} \mathrm{CN}$ & 300 & 97 & 27 \\
\hline $\mathbf{4}$ & Montmorillonite-KSF & Solvent-free $/ 100^{\circ} \mathrm{C}$ & 150 & 93 & 41 \\
\hline $\mathbf{5}$ & $\mathrm{g}^{-} \mathrm{C}_{3} \mathrm{~N}_{4} @ \mathrm{~L}$-arginine & $\mathrm{EtOH} /$ reflux & 15 & 96 & $\begin{array}{l}\text { This } \\
\text { Work }\end{array}$ \\
\hline
\end{tabular}

(d) Reaction condition: 4-chlorobenzaldehyde $(1 \mathrm{mmol})$, isotonic anhydride $(1 \mathrm{mmol})$, and ammonium acetate (1 $\mathrm{mmol}), \mathrm{g}-\mathrm{C}_{3} \mathrm{~N}_{4} @ \mathrm{~L}$-arginine catalyst $(20.00 \mathrm{mg})$, and ethanol $(7 \mathrm{~mL})$ under reflux.

\section{Figures}




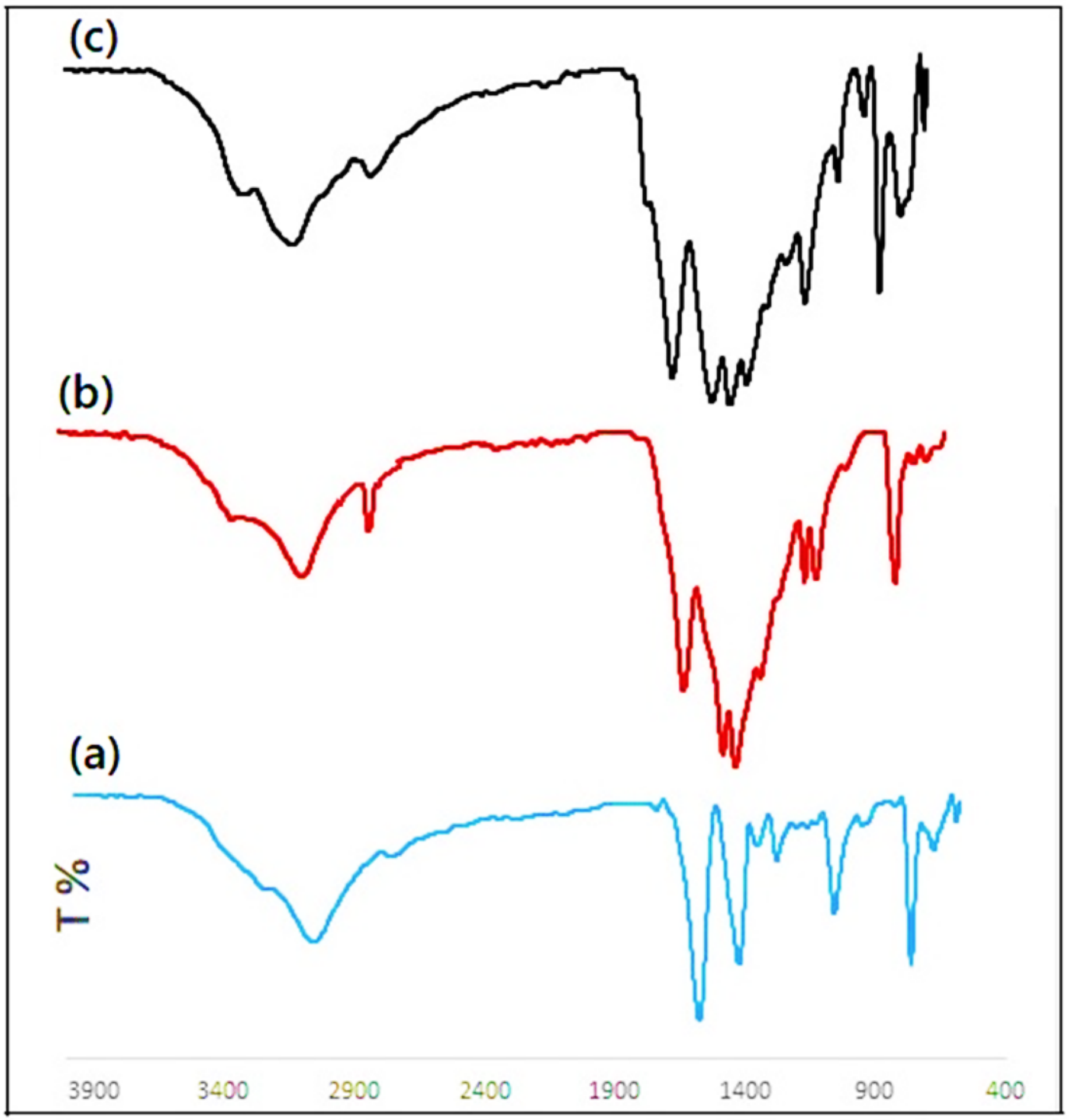

Figure 1

FT-IR spectra of (a) nanosheets g-C3N4, (b) modified g-C3N4, (c) g-C3N4@L-arginine. 

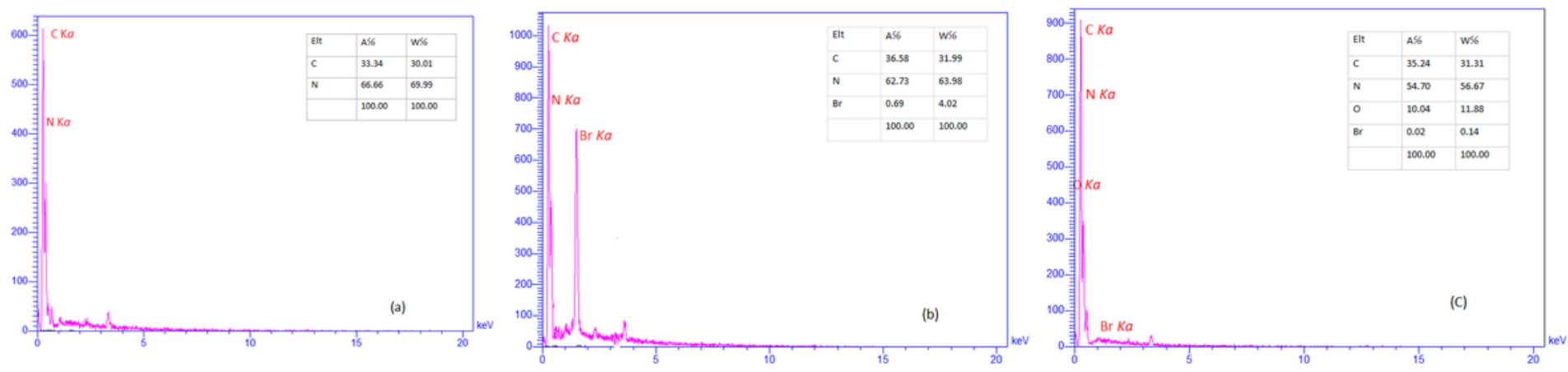

Figure 2

EDX spectrum of (a) nanosheets g-C3N4, (b) modified g-C3N4, (c) g-C3N4@L-arginine.
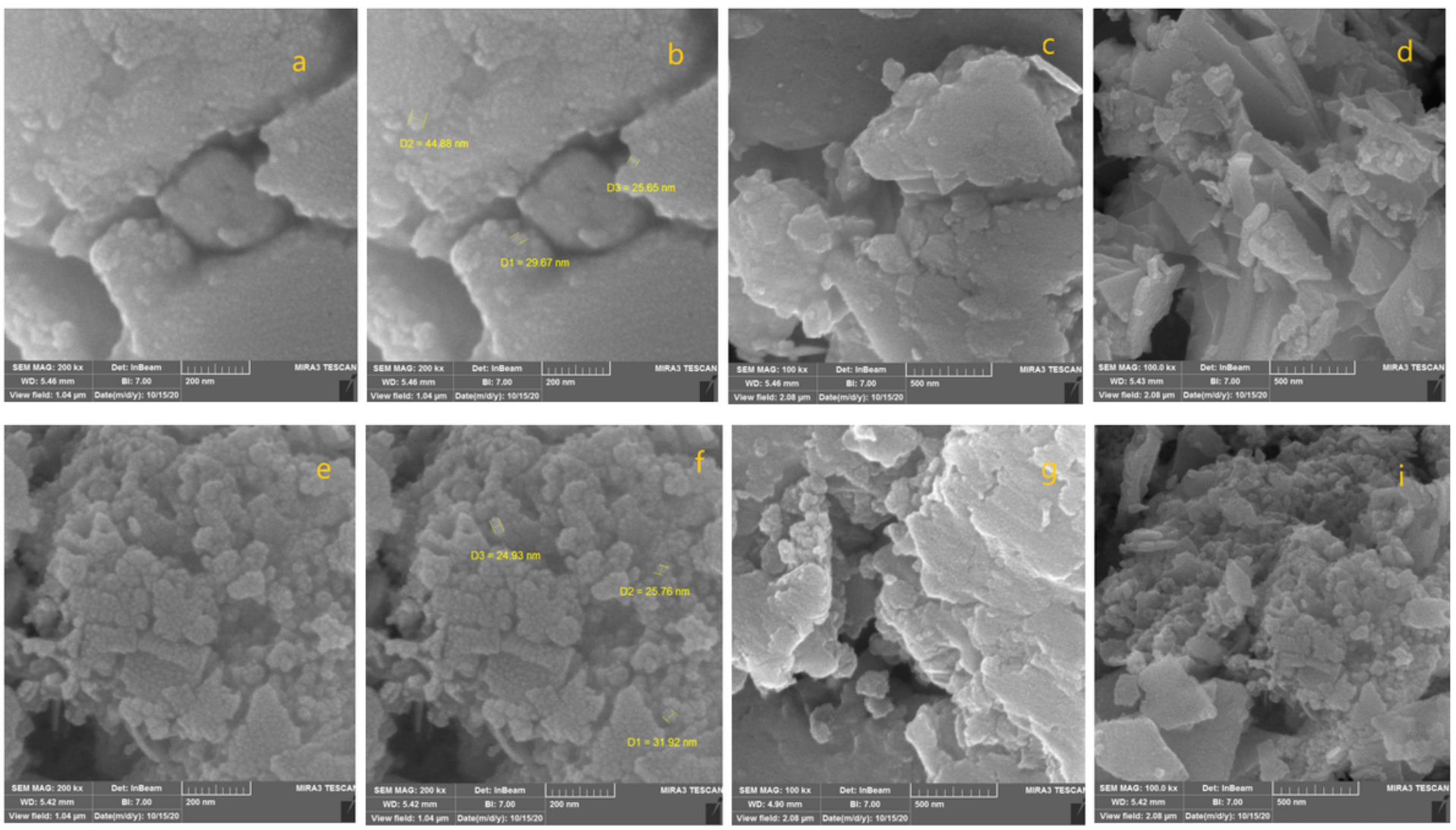

\section{Figure 3}

FE-SEM image of nanosheets g-C3N4 (a, b, c, and d), and g-C3N4@L-arginine (e, f, g, i). 


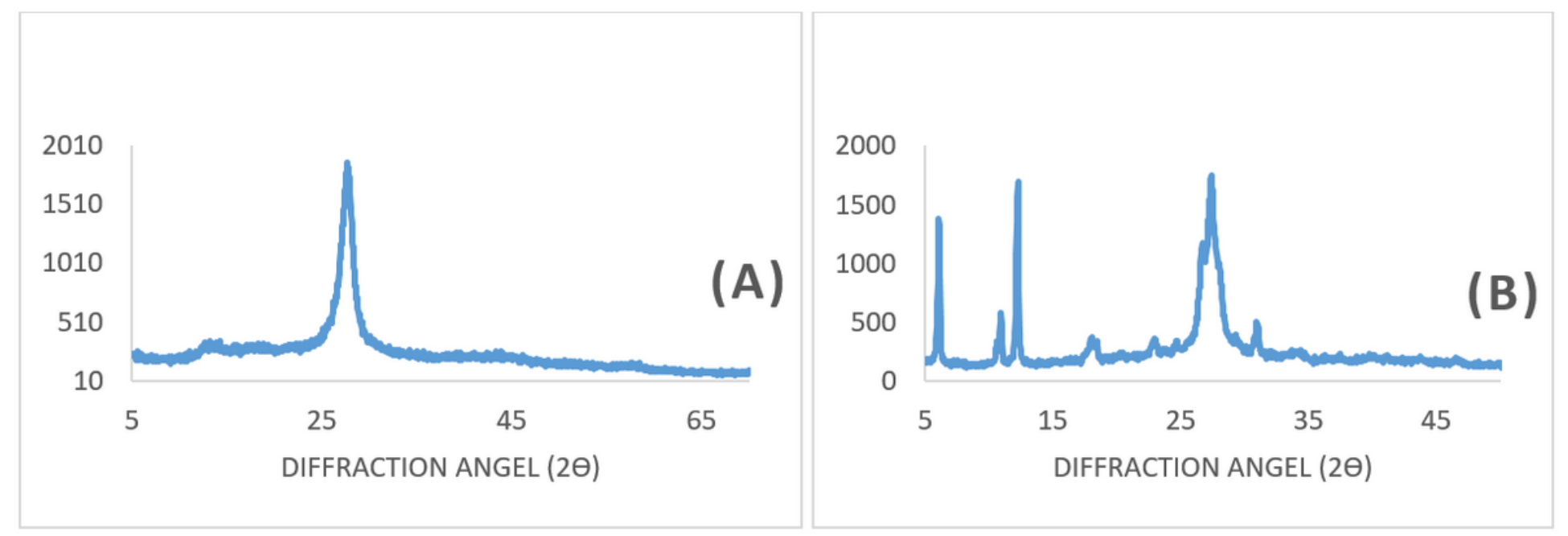

\section{Figure 4}

XRD pattern of (a) nanosheets g-C3N4, (b) g-C3N4@L-arginine.

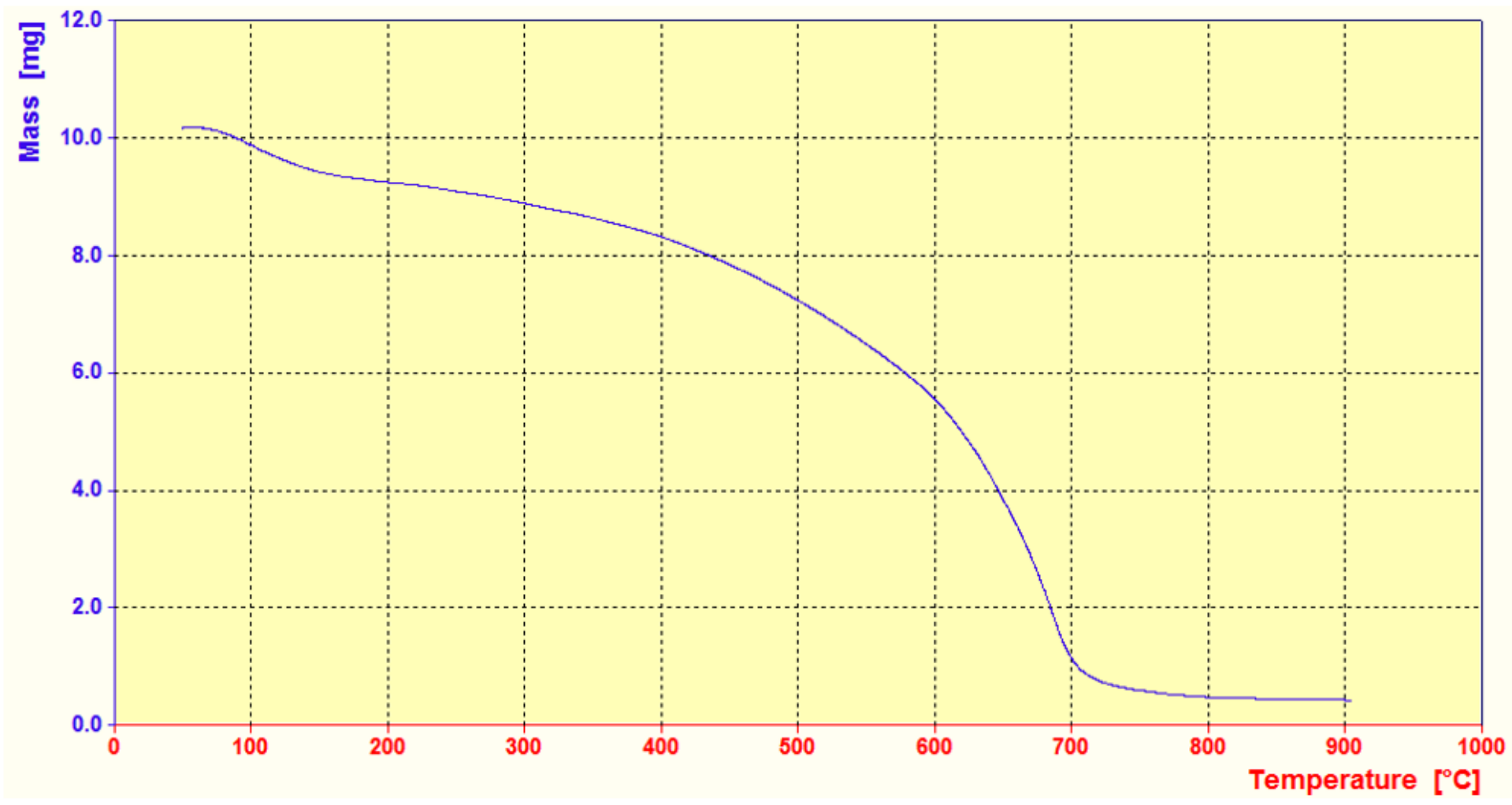

Figure 5

TGA analysis of g-C3N4@L-arginine. 


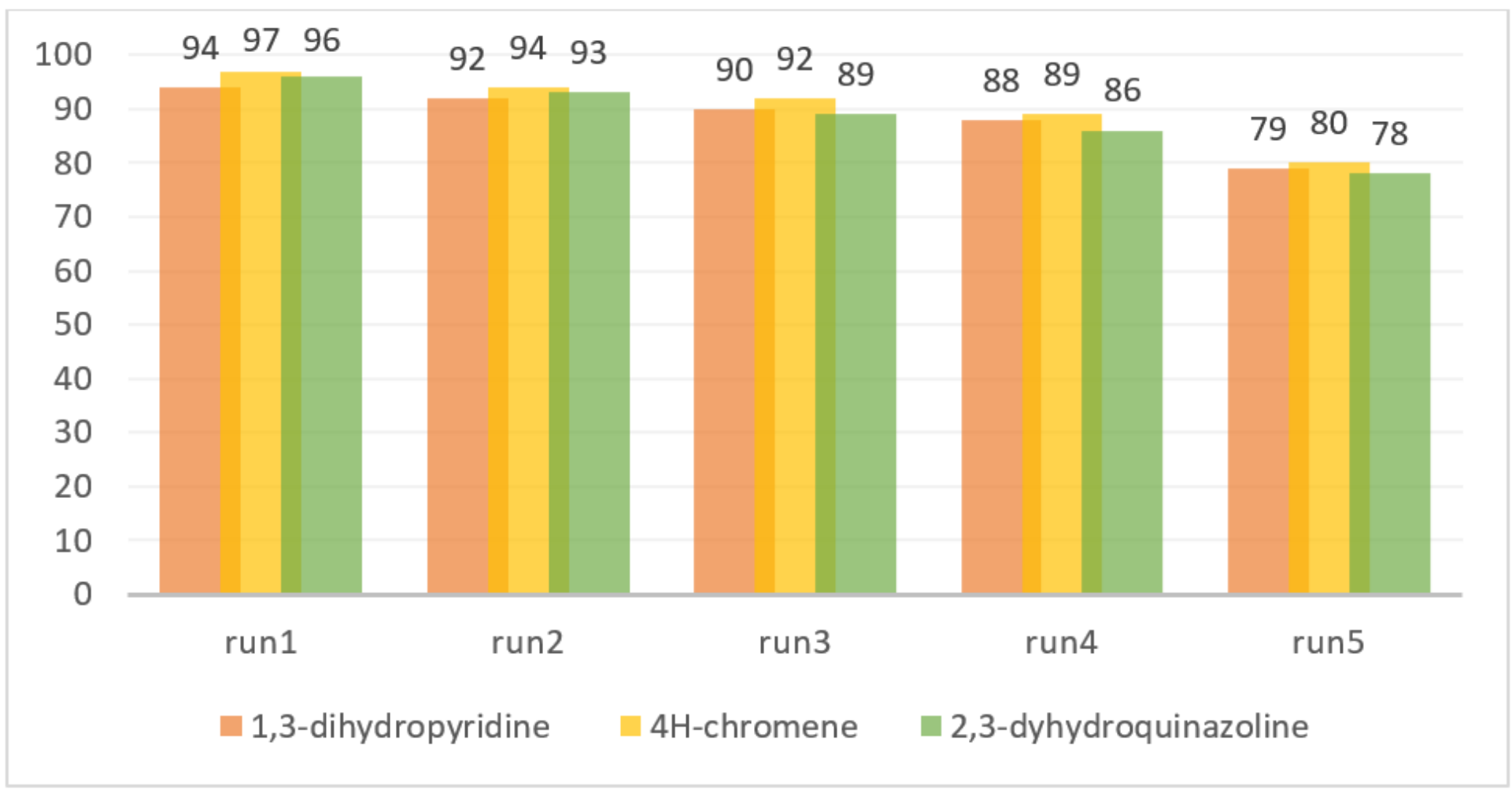

\section{Figure 6}

Examination of g-C3N4@L-arginine reusability in synthesis of 1, 3-dihydropyridine 5b, 4H-chromene 9b, and 2, 3-dihydroquinazoline 13b.
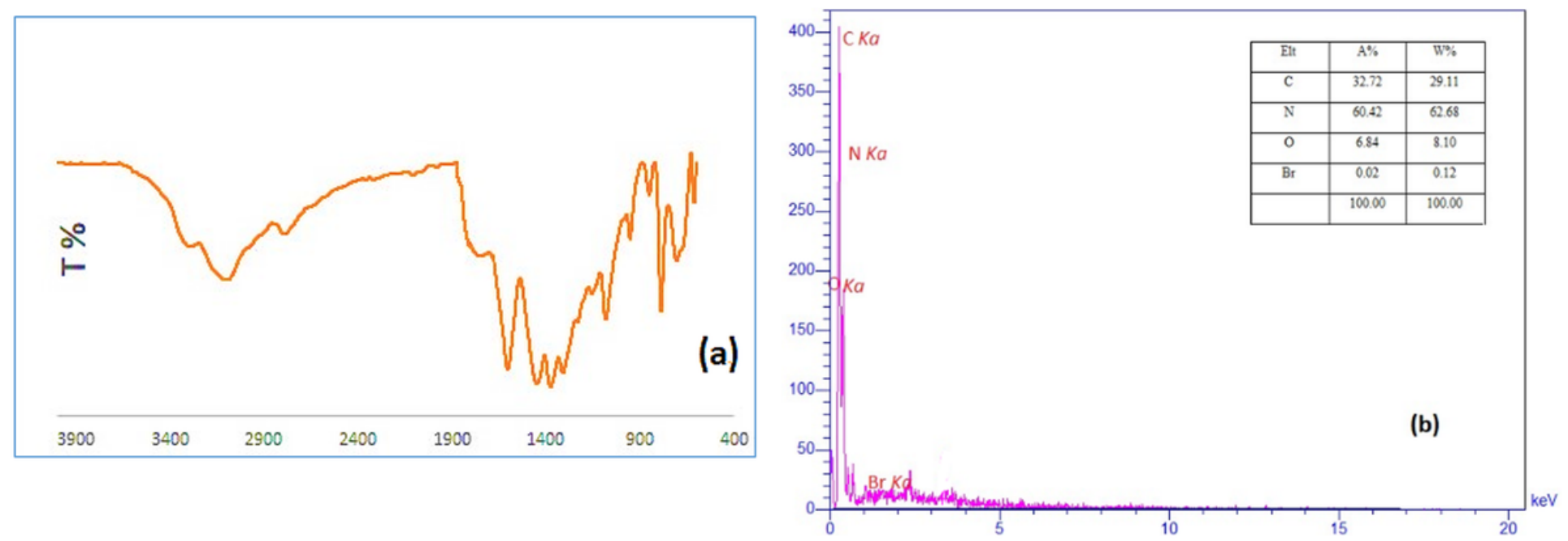

Figure 7

EDX (b) and FT-IR spectra (a) of g-C3N4@L-arginine after the five-times recycling

\section{Supplementary Files}

This is a list of supplementary files associated with this preprint. Click to download. 
- ElectronicSupplemntaryInformation1.docx

- Scheme1.png

- Scheme2.png 